\title{
Robledo, Hernández Gabriela Patricia (2010), Identidades femeninas en transformación. Religión y género entre la población indígena urbana en el altiplano chiapaneco, México: Publicaciones de la Casa Chata-CIESAS.
}

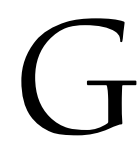
abriela Robledo nos sorprende de nuevo con este texto producto de una reflexión que refleja la madurez de sus preocupaciones antropológicas, mismas que reaparecen ahora como una profundización de aquella su primera publicación Disidencia y religión. Los expulsados de San Juan Chamula, publicada en 1997.

En esta entrega, Identidades femeninas en transformación. Religión y género entre la población indígena urbana en el altiplano chiapaneco, la autora nos ofrece una nueva mirada sobre un tema que ha sido no sólo de gran interés para ella misma, sino el hito de muchas discusiones antropológicas y sociológicas contemporáneas: la diversificación del campo religioso en el altiplano chiapaneco y lo que esta diversificación ha coadyuvado para los cambios socioculturales de la población indígena. Esta vez se trata de indígenas que comparten, con una gran diversidad de actores, un espacio urbano, pluriétnico, multisimbólico, por lo mismo, entramado de relaciones sociales extremadamente complejo.

Para darnos cuenta de los cambios surgidos en las relaciones de género entre los indígenas inmigrantes en San Cristóbal de Las Casas, la autora recrea esa complejidad actual de la Región del altiplano chiapaneco y más específicamente de esta ciudad. Trayectorias itinerantes, sucesivas conversiones religiosas, conversos que han tocado las puertas de varias congregaciones. Este peregrinaje indígena por diversas congregaciones religiosas constituye otro camino, con distintos vericuetos, otra manera de buscar y por otras causas a las señaladas por Hervieu-Léger en sociedades altamente diferenciadas. Sin embargo, el texto hace ver que algo tiene que ver esta movilidad con la dinámica de la ciudad, sus estereotipos sociales, su propio y moderno y, al mismo tiempo, anquilosado engranaje y desengranaje con un mundo globalizado.

Aunque las pautas que rigen el comportamiento de hombres y mujeres inmigrantes indígenas en esta ciudad continúan, en cierta medida, marcadas por los patrones de género que rigen el mundo tradicional, la vivencia en este espacio urbano propicia en sus nuevas interacciones una paulatina transformación, de tal manera que se mezclan viejos valores con las nuevas dinámicas e intereses de esta población indígena sumamente ágil y creativa. Este estudio muestra una población que ha crecido en los últimos años, por diversas razones, en forma acelerada y que en su proceso de adaptación está cambiando no sólo la fachada, el aspecto de un espacio urbano, que ha inyectado a la ciudad un dinamismo sin antecedentes.

Este inextricable panorama aparece en este estudio con una especial sensibilidad. El hecho de observar 
esta complejidad desde un punto del horizonte, es decir, desde las transformaciones que se están dando en las identidades femeninas indígenas y por ende, en las relaciones de género y en las relaciones familiares de los inmigrantes; le permiten mostrar la particular diversidad religiosa que se está produciendo no sólo en San Cristóbal, sino en general, en la región. Una diversidad religiosa dada no sólo por la proliferación de congregaciones cristianas de variadas denominaciones, sino por la importante incidencia y diversificación de la religión católica, quien en su vertiente de Iglesia Autóctona, se encuentra ahora también presente en la ciudad como producto de las mismas inmigraciones indígenas y como una innovación.

Los indígenas inmigrantes, sostiene la autora, han convertido la adhesión a estas congregaciones en un nicho de transformaciones de la dinámica familiar y en particular, de las identidades femeninas. Para explicar estas mutaciones toma como casos de estudio la participación indígena en dos grupos religiosos: La Asamblea Apostólica de la fe en Cristo Jesús, de carácter pentecostal; y la congregación del templo católico El Divino Pastor, asociado a las diaconías y a la iglesia autóctona; dos distintas fuentes de identificación religiosa entre los inmigrantes indígenas en San Cristóbal.

Una vez instalado en la ciudad, el inmigrante indígena se ve obligado a congregarse, a anular las barreras que antes lo separaban de las otras poblaciones indígenas para constituirse en una sola etnia: la indígena. Y esta etnia está creando un modelo de interacción, lazos de comunión de tipo communitas. La tesis que guía este trabajo es que la pertenencia a una congregación religiosa permite a los inmigrantes indígenas crear pequeñas comunidades que funcionan como una red de ayuda mutua y de lazo social fundado en la emocionalidad. Se trata de redes que se tornan en un sentido de pertenencia y que proveen de una ética más apta para hacer frente a los problemas que hay que enfrentar en la ciudad.
La autora se preocupa por entender cómo es este tipo de sociabilidad que los inmigrantes indígenas, de las más diversas procedencias, se afanan en construir. A todas luces nos muestra cómo al instalarse en la ciudad, los antiguos lazos fundados en una costumbre se rompen para dar paso a otro tipo de vínculos sociales adaptados a las nuevas vivencias sociales.

Porque esta ciudad los recibe, sí, pero con su a veces, cruel rudeza y su laberíntico enredo social. Lanzados al engranaje de la peculiar modernidad de San Cristóbal de Las casas, los indígenas inmigrantes son tironeados por los distintos ritmos históricos y poblacionales que coexisten en este lugar. Si los indígenas encuentran en San Cristóbal de Las Casas el viejo esquema de una sociedad explotadora y racista, también les ofrece espacios de participación creados precisamente a favor de ellos. Asociaciones civiles, gubernamentales, cooperativas, personas que intentan darles y enseñarles un trato digno, extranjeros o inmigrantes venidos de otras partes de México en su gran mayoría trabajando en organizaciones no gubernamentales compiten con aquellos sectores de la población local todavía enraizados en los esquemas de percepción del indígena que produjo la región desde La Colonia.

Es en medio de este paisaje donde queda inserta la conformación de una transformadora creación de sociabilidad entre indígenas de diversas regiones del altiplano chiapaneco, ahora asentados en la ciudad. Lo que se observa en el libro es una fuerte tendencia de este sector de la población a crear asociaciones tipo communitas propia de las sociedades modernas y para que esto ocurra, las congregaciones religiosas tienen una determinante participación. Por esta razón, encontramos en este estudio una descripción muy bien lograda de la pluralidad y las características del cambio religioso entre la población indígena urbana, basada en estimaciones cuantitativas, que dan cuenta tanto de la diversidad de denominaciones que supone el cristianismo evangélico, como de la iglesia católica 
quien, entre otras opciones, ofrece ahora en la ciudad una pastoral indianista.

Una propuesta de este trabajo es que el cambio religioso permite la acción colectiva y la revitalización de la etnicidad. Dichas filiaciones son vistas como religiosidades capaces de expresar proyectos colectivos y dar origen a cierto tipo de liderazgos a hombres y mujeres en un contexto donde se dan condiciones de racismo y exclusión social.

"En la ciudad, señala la autora literalmente, se reelaboran las identidades, nuevas reglas prescriben los vínculos sociales a partir de los cuales se prescriben los comportamientos socialmente aceptados. Las diferencias entre etnias indígenas se minimizan, lo indígena se unifica frente a la identidad ladina".

Cómo toda investigación, ésta nos empuja a formularnos nuevas interrogantes: ies tan tajante la división étnica de esta ciudad? ¿Constituyen, los ladinos, una única y homogénea otredad o, más bien, múltiples otredades constituidas por los "coletos" de alcurnia, los de barrio, los pobres, los más ricos, los extranjeros atraídos por los ideales de una sabia mayanidad, por los mismos mexicanos de otras partes de la república que han llegado a San Cristóbal atraídos por el EZLNávidos de una dignificación del indígena?

Por los datos e interpretaciones expuestos en este trabajo, se comprende que es justamente dicha heterogeneidad la que genera una multiplicidad de posibilidades que ayudan en los procesos de independencia y autonomía de las mujeres, además del espacio de la congregación religiosa. Si la vulnerabilidad de las mujeres en la ciudad es más grande porque se rompen los lazos comunitarios, también es cierto que algunas de ellas pueden conquistar una mayor capacidad de decisión, una posibilidad de autonomía y de un trato más equitativo entre hombres y mujeres, una disminución de la violencia en el seno familiar.

Las reflexiones de este texto hacen ver que la participación femenina en cooperativas de artesanías, comités de gestión de servicios en las colonias y en organizaciones no gubernamentales con programas dirigidos a mujeres, en organizaciones de carácter amplio y productivo, las provee de herramientas no sólo para cuestionar los esquemas de género y de socialización tradicionales, sino también para ejercer otras formas de liderazgo femenino. La posibilidad de las mujeres de formar parte de los diferentes comités de gestión y servicios está abriendo espacios de intervención femenina en la vida pública, pero también es cierto que no todas pueden acceder a estos ámbitos y una gran parte de ellas continúan empleándose como domésticas, percibiendo bajísimos salarios y reproduciendo relaciones de desigualdad social. La integración de la mujer indígena inmigrante al medio citadino, muestra este estudio, va a varias velocidades y en diferentes grados de adaptación y cambio. Sin embargo, la conclusión general de esta investigación es que la migración a la ciudad influye considerablemente en la reconstrucción de las relaciones de género en los hogares de las familias indígenas. Aunque la figura masculina sigue representando la autoridad, las mujeres tienen la posibilidad de ampliar su espacio de socialización. Las redes de interacción urbanas les brindan recursos materiales y simbólicos que ellas pueden utilizar para mejorar su posición en relación a la pareja y en el interior de sus hogares.

Este cambio no se da sin consecuencias, plantea la autora. Al perder la estructura de la familia extensa, las uniones entre indígenas se tornan más frágiles. Muchas mujeres están asumiendo la jefatura de sus hogares, ante la ausencia de los hombres que migran en busca de empleo, o simplemente ante la ruptura de la relación conyugal, más propicia en este nuevo contexto de socialización. Otro hecho nuevo señalado en el texto es la participación de las mujeres en espacios públicos, en las agencias de gobierno como de las organizaciones no gubernamentales, mismas que promueven los derechos de las mujeres y la formación de un liderazgo femenino, así como el cambio en las representaciones y prácticas de ser mujer. 
Pero quizá como ningún otro espacio público, el religioso genera o hace posible innovaciones más profundas. La ausencia de los cónyuges, quienes parten la mayoría de las veces en busca de trabajo, hace de estas pequeñas comunidades un lugar vital de socialización femenina, fundado en el lazo emocional. Para los hombres, la congregación religiosa significa, además un espacio de liderazgo y de carrera política. El hecho de que la mayoría de la población indígena urbana sobreviva en condiciones de vulnerabilidad, convierte a la congregación religiosa en una red de apoyo espiritual y material. Esto explica, en cierta mediada el alto crecimiento de las confesiones pentecostales de diversas denominaciones en las colonias indígenas urbanas, el éxito de la iglesia autóctona dirigida por indígenas y las múltiples conversiones por las que a veces opta el inmigrante indígena.

Estos espacios -sostiene Gabriela Robledopermiten a las indígenas cuestionar las normas que prevalecen en la "costumbre" de cada comunidad. Se constituye en una oportunidad para ensayar nuevas formas de conducta más dignas y útiles, otras formas de asociación y de vínculos sociales.

Los cambios descritos han requerido de un escenario. La autora dedica un importante apartado para brindar al lector un contexto histórico regional que le permita entender las causas y orígenes de estas migraciones a San Cristóbal. Los procesos migratorios son vistos con un gran angular que permite comprender los problemas económicos, religiosos y políticos que impulsaron a grandes masas de población indígena a migrar hacia San Cristóbal, pero también hacia otros destinos.

En términos generales el texto es optimista, gran cualidad si tomamos en cuenta la crudeza con que es descrita la condición del indígena inmigrante en la ciudad. Su optimismo permite enfatizar no sólo los conflictos que originaron la migración hacia la ciudad, los bretes que se dan actualmente entre la tradición y los procesos de cambio, la desintegración cultural, los males asociados a la migración y a la conversión religiosa; sino, sobre todo, pondera la creatividad y la vitalidad de este grupo que da otra fisonomía a la demografía de San Cristóbal. Ya sean indígenas inmigrantes pentecostales o católicos de la nueva pastoral, hombres y mujeres trabajan para remodelar sus lazos interétnicos, trabajan en la creación de nuevas formas de asociación y cambian, de esta manera, su ser social y cultural.

Astrid Maribel Pinto Durán CESMECA-UNICAH 